\title{
Hearing assessment in high-risk neonates by brain stem evoked auditory response (BERA) at a teaching hospital in rural Telangana
}

\author{
Sudharahan Raj C $C^{1}$ Reddy S.V ${ }^{2}$ \\ ${ }^{1}$ Dr. Sudharahan Raj. C, Associate Professor, Department of Pediatrics, MediCiti Institute of Medical Sciences, Ghanpur, \\ Medchal, ${ }^{2}$ Dr.Venkat Reddy.S, Consultant, Pediatrics, Navodaya Hospital, Hyderabad.
}

Address for Correspondence: Dr.Venkat Reddy. S, Consultant, Pediatrics, Navodaya Hospital, Hyderabad.

Email ID: neelimasudharshan@gmail.com

\begin{abstract}
Introduction: Severe pre-lingual hearing impairment has important consequences for language acquisition, communication, and cognitive, social and emotional development. Indeed evidence is increasing that even moderate hearing loss in very young children can be detrimental. Brainstem evoked response audiometry (BERA), when used and interpreted properly, provide a powerful method of obtaining reliable estimates of auditory sensitivity in infants, young children, and other individuals who cannot or will not provide reliable results on behavioral hearing tests. Materials \& Methods: In this study 110 high risk neonates having one or more risk factors, according to the criteria stated by American Academy of Pediatrics, JCIH 2007 were selected from Newborn unit, of MIMS, Ghanpur. The high risk neonates were subjected to BERA testing in a sound proof room in our study, $30 \mathrm{~dB}$ is taken as cutoff for normal auditory threshold. Results: Mean birth weight of neonates studied was $2.60 \pm 0.67 \mathrm{~kg}$. Mean age of neonates at which first BERA done is 19.32 \pm 11.3 days. Hyperbilirubinemia requiring Exchange transfusion and TORCH infection were identified as significant risk factors with p-values 0.028 and 0.011 respectively. Conclusion: Hearing impairment is common in high risk NICU graduates. Bilateral hearing impairment is more common than unilateral. All high risk infants must be screened for hearing impairment prior to discharge and retesting of infants with abnormal BERA after 3 months and subsequently if necessary. Newborn screening is mandatory to identify hearing loss in the prelinguistic period to reduce the burden of handicap in the community.
\end{abstract}

Key words: Neonate, BERA, Hearing impairment, Risk factors.

\section{Introduction}

Severe pre-lingual hearing impairment has important consequences for language acquisition, communication, and cognitive, social and emotional development. Indeed evidence is increasing that even moderate hearing loss in very young children can be detrimental [1]. Hearing loss presents high incidence, affecting around 3 out of every 1000 live births, and 2 to 4 out of every 100 newborns leaving the neonatal intensive care unit (NICU). The initial signs of hearing loss are very subtle and systematic neonatal hearing screening is the most effective means of early detection.

Manuscript received: $15^{\text {th }}$ July 2016

Reviewed: $25^{\text {th }}$ July 2016

Author Corrected; $10^{\text {th }}$ August 2016

Accepted for Publication: $22^{\text {nd }}$ August 2016
Early diagnosis and immediate intervention are decisive factors in the development and prognosis of these children [2].

During the past 30 years, infant hearing screening have been attempted with a number of different methods using behavioral and physiological measures. Brainstem evoked response audiometry is one of the objective methods of hearing screening. Brainstem evoked response audiometry, when used and interpreted properly, provide a powerful method of obtaining reliable estimates of auditory sensitivity in infants, young children, and other individuals who cannot or will not provide reliable results on behavioral hearing tests [3]. 
The 2007 POSITION Statement from the Joint Committee on Infant Hearing recommended that neonates who are in ICUs for 5 days, or who have risk factors and a shorter stay, undergo hearing screening with (automated) auditory brainstem response (ABR) testing [1]. If the neonates do not pass the tests, then a full diagnostic ABR assessment is to be performed by an experienced audiologist [4].

Currently, the average age of detection of significant hearing loss is 14 months. The American Academy of Pediatrics supports the statement of the Joint Committee on Infant Hearing (1994), which endorses the goal of universal detection of hearing loss in infants before 3 months of age, with appropriate intervention no later than 6 months of age.

Universal detection of infant hearing loss requires universal screening of all infants. Screening by high risk registry alone (eg, family history of deafness) can only identify $50 \%$ of newborns with significant congenital hearing loss. Reliance on physician observation and/or parental recognition has not been successful in the past in detecting significant hearing loss in the first year of life [5].

The first three years of life are most important for speech and language acquisition. Animal studies have shown that early auditory deprivation interferes with the development of neural structures necessary for hearing. The goal of early identification and intervention is to minimize the adverse effects. Neonatal and infant screening programs using test procedure like Otoacoustic (OAE) emission and Auditory brain stem response (ABR) have been established worldwide for this purpose [6].

This study was undertaken to know the incidence of BERA abnormality in high risk neonates, to reassess
BERA abnormality after 3 months and to analyze the associated risk factors.

\section{Materials and Methods}

In this study 110 high risk neonates having one or more risk factors, according to the criteria stated by American Academy of Pediatrics, JCIH 2007 were selected from Newborn unit, of MIMS, Ghanpur.

Study period : January 2015 to June 2016.

Place of study: Department of Neonatology, MIMS, Ghanpur

Study design: Prospective, observational and descriptive study

Study was approved by institutional ethical committee.

\section{Inclusion criteria}

1. In utero infections (toxoplasmosis, rubella, cytomegalovirus, herpes simplex virus infections, and syphilis).

2. Gestational age $<37$ weeks. Birth weight < 1500gms.

3. Family history of hearing impairment.

4. Hyperbilirubinemia at serum levels requiring phototherapy and or exchange transfusion.

5. Ototoxic medications (ex; aminoglycosides alone or in combination with loop diuretics) Meningitis.

6. HIE stage 2 or 3 (Sarnat Sarnat staging).

7. Mechanical ventilation lasting 5 days or longer. Craniofacial anomalies.

\section{Exclusion criteria}

1. Severe multiple anomalies incompatible with life Untreated otitis externa

2. Atresia or stenosis of external ear canals of both ears.

\section{Methodology}

There were 110 high risk neonates satisfying the inclusion criteria during the study period. Written informed consent was taken from the parents after explaining the procedure and its significance in their vernacular language. Detailed history and thorough ENT examination was done before the procedure.

BERA recording: The high risk neonates were subjected to BERA testing in a sound proof room. Test was performed about 30 minutes post feeding and while they were in natural sleep. 
Procedure: Procedure was performed at the time of discharge and when the baby is sleeping. The skin at the point of placement of electrodes was cleaned with abrasive strip. Recording of BERA was carried out in a quiet and semidarkened room. Surface electrodes were placed at the vertex, both mastoids and forehead.

The resistance was kept below 5K. Monaural auditory stimulus consisting of rarefaction clicks of 100 microseconds were delivered through electrically shielded earphones at the rate of $11.1 / \mathrm{sec}$. contralateral ear was masked with pure white noise of $40 \mathrm{db}$.

A band pass of $15-3000 \mathrm{~Hz}$ was used to filter out undesirable frequencies in the surroundings. Responses to 2000 click presentations were averaged. The hearing loss was quantified as mild, moderate, severe and profound. An abnormal BERA is repeated after three months.

Grades of hearing impairment by WHO [7].

\begin{tabular}{|c|c|}
\hline Grade of hearing impairment & Threshold level (dB) \\
\hline No impairment (0) & 25 or better \\
\hline Slight impairment (1) & $26-40$ \\
\hline Moderate impairment (2) & $41-60$ \\
\hline Severe impairment (3) & $61-80$ \\
\hline Profound impairment (4) & $>80$ \\
\hline
\end{tabular}

In our study, $30 \mathrm{~dB}$ is taken as cutoff for normal auditory threshold (i.e., minimum intensity of Auditory click stimulus required to elicit a wave $\mathrm{V}$ of BERA response.)

\section{Results}

The present study was conducted in Department of Neonatology, MediCiti Institute of Medical Sciences. 110 high risk neonates were studied at discharge and in those babies with abnormal BERA findings, repeat BERA was done after 3 months. Table: 1 gives an overview on neonatal risk factors in this study.

Table- 1: Neonatal risk factors in the study $(n=110)$.

\begin{tabular}{|c|c|c|}
\hline Risk factors & $\begin{array}{c}\text { Number of } \\
\text { Cases }\end{array}$ & Percentage (\%) \\
\hline TORCH infection & 2 & 24.5 \\
\hline Preterm & 27 & 14.5 \\
\hline Hyperbilirubinemia - Exchange & 16 & 30.9 \\
\hline Hyperbilirubinemia - Phototherapy & 34 & 3.6 \\
\hline Meningitis & 4 & 17.3 \\
\hline HIE & 19 & 13.6 \\
\hline Ototoxic medications (Amikacin) & 15 & 60.9 \\
\hline
\end{tabular}


Note: TORCH- Toxoplasma, Rubella Cytomegalovirus Herpes virus infection, HIE- Hypoxic Ischemic Encephalopathy. During the study period, the number of neonates with craniofacial anomalies and family history of hearing loss was zero. So, those two risk factors couldn't be studied.

Among 110 high risk neonates, 75 (68.2\%) were males, and 35 (31.8\%) females. Mean birth weight of neonates studied was $2.60 \pm 0.67 \mathrm{~kg}$. Mean age of neonates at which first BERA done is $19.32 \pm 11.3$ days. Out of 110 high risk neonates, $27(24.54 \%)$ were preterm and $83(75.45 \%)$ term babies. $59(53.64 \%)$ babies got delivered by caesarean and $51(46.36 \%)$ normal delivery.

A neonate is considered to have normal threshold if wave $\mathrm{V}$ was present at $30 \mathrm{~dB}$ in both ears. Mild hearing impairment at threshold between $30 \mathrm{~dB}$ to $40 \mathrm{~dB}$, moderate between $40 \mathrm{~dB}$ to $60 \mathrm{~dB}$, severe between $60 \mathrm{~dB}$ to $80 \mathrm{~dB}$ and profound more than $80 \mathrm{~dB}$.

On univariate analysis considering BERA as normal and abnormal response, Hyperbilirubinemia requiring Exchange transfusion and TORCH infection were identified as significant risk factors with p-values 0.028 and 0.011 respectively.

These two risk factors were subjected to logistic regression analysis and both were statistically significant. Analysis of various variables in relation to BERA is shown in table 2.

Quantitative data is analyzed by T-test. Of which Bilirubin levels are statistically significant in correlation to abnormal BERA, with p-value 0.000 . Of the 110 high risk neonates 50 had hyperbilirubinemia ranging from 14-40 mg/dl.

Table-2: Analysis of variables with quantitative data in relation to BERA.

\begin{tabular}{|c|c|c|c|c|c|c|c|}
\hline & Range & BERA & Num ber & Mean & $\begin{array}{c}\text { Std. } \\
\text { Deviation }\end{array}$ & $\begin{array}{l}\text { Std. error } \\
\text { Mean }\end{array}$ & P-value \\
\hline \multirow[t]{2}{*}{ Birth weight } & \multirow{2}{*}{$\begin{array}{c}870-3900 \\
\text { grams }\end{array}$} & Normal & 103 & 2606.31 & 682.197 & 67.219 & \multirow[t]{2}{*}{0.887} \\
\hline & & Abnormal & 7 & 2568.57 & 568.988 & 215.057 & \\
\hline \multirow{2}{*}{$\begin{array}{c}\text { Gestational } \\
\text { Age }\end{array}$} & \multirow{2}{*}{$\begin{array}{l}28-40 \\
\text { weeks }\end{array}$} & Normal & 103 & 37.27 & 2.935 & 0.289 & \\
\hline & & Abnormal & 7 & 37.00 & 2.160 & 0.816 & 0.811 \\
\hline \multirow{2}{*}{$\begin{array}{c}\text { Peak } \\
\text { Bilirubin }\end{array}$} & \multirow{2}{*}{$\begin{array}{l}14-40 \\
\mathrm{Mg} / \mathrm{dl}\end{array}$} & Normal & 47 & 22.46 & 4.625 & 0.675 & \multirow[t]{2}{*}{0.000} \\
\hline & & Abnormal & 3 & 33.53 & 6.712 & 3.875 & \\
\hline
\end{tabular}

\begin{tabular}{|c|c|c|c|c|c|}
\hline & T & Df & \multicolumn{2}{|c|}{$\begin{array}{c}\text { Significan ce } \\
\text { (p-value) }\end{array}$} & \multicolumn{2}{|c|}{ 95\% of Confidence Interval of the } \\
& & & & Lower & Upper \\
\hline Birth Weight & .143 & 108 & .887 & -485.954 & 561.432 \\
\hline Gestational Age & .240 & 108 & .811 & -1.971 & 2.515 \\
\hline Peak Bilirubin & -3.929 & 48 & .000 & -16.734 & -5.405 \\
\hline
\end{tabular}

Out of 110 high risk neonates studied, $10(9.09 \%)$ had hearing impairment at discharge and when repeated after 3 months only $7(6.36 \%)$ had hearing impairment. (fig. 1$)$ 


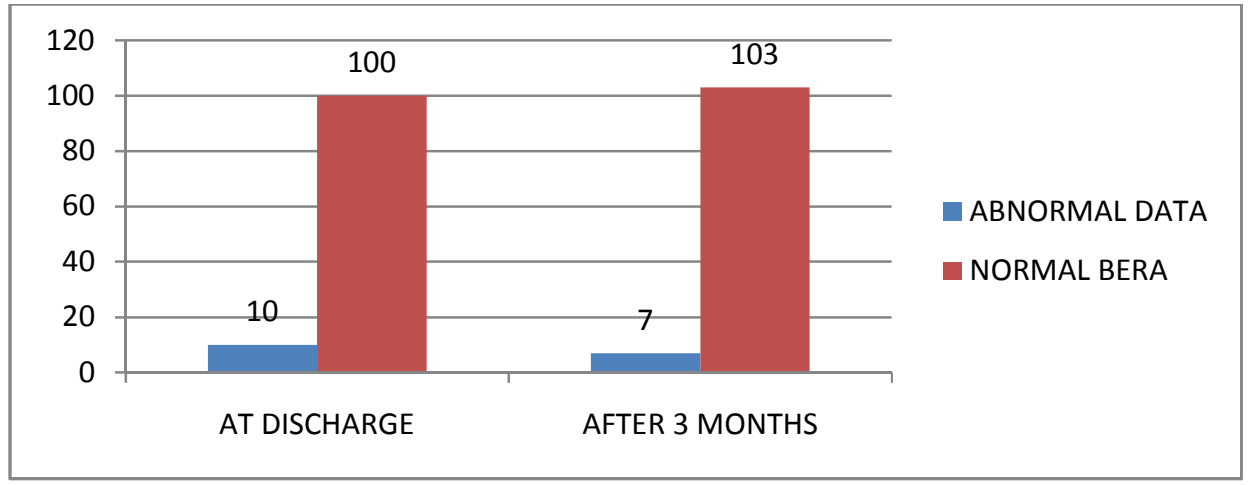

Fig-1: Incidence of abnormal BERA in high risk neonates

In this study most of the neonates with abnormal BERA had single risk factor. In this study bilateral hearing impairment is predominant $(7.6 \%)$ than unilateral.

Of the 110 neonates, 2 had congenital rubella infection. 16 neonates required exchange transfusion for hyperbilirubinemia. Of them 2 had moderate hearing impairment and 1 had severe hearing impairment? On repeating BERA after 3 months, some showed improvement in degree of hearing.

34 neonates required phototherapy for hyperbilirubinemia. Of them one had mild hearing impairment at discharge. None of them had hearing impairment when repeated after 3 months. There was no significant association between hyperbilirubinemia in phototherapy range and BERA abnormality.

One of the four neonates with meningitis had hearing impairment. He had mild hearing impairment in both ears and persisted after 3 months. Of the 19 neonates with hypoxic ischemic encephalopathy (HIE), 4 had HIE stage- 3 and 15 had HIE stage- 2. Staging was done by Sarnat and Sarnat scoring. Of the 110 neonates, 15 were on mechanical ventilation for $>5$ days. One of the 15 neonates has hearing impairment. At discharge he had moderate hearing impairment and when repeated after 3 months he has mild hearing impairment. Child has unilateral (right ear) hearing impairment.

Table-3: Analysis of risk factors in relation to BERA.

\begin{tabular}{|c|c|c|c|c|c|c|c|}
\hline Risk factor & Total No. & Normal & \multicolumn{2}{|c|}{$\begin{array}{c}\text { Abnormal BERA at } \\
\text { discharge }\end{array}$} & \multicolumn{2}{|c|}{$\begin{array}{c}\text { Abnormal BERA after } \\
\text { months }\end{array}$} & $\begin{array}{c}\text { Logistic } \\
\text { regression } \\
\text { analysis }\end{array}$ \\
\hline & & & & No. & p-value & No. & p-value \\
\hline TORCH Infection & 2 & 1 & 1 & 0.042 & 1 & 0.011 & 0.027 \\
\hline Preterms & 27 & 25 & 2 & 0.726 & 0 & 0.119 & 0.028 \\
\hline Hyperbilirubinemia \\
DVET
\end{tabular}


Research Article

\begin{tabular}{|c|c|c|c|c|c|}
\hline & Df & Significate & \multirow{2}{*}{ EXP(B) } & \multicolumn{2}{|c|}{ 95\% confidence interval for EXP(B) } \\
\cline { 3 - 6 } & & & & Lower & Upper \\
\hline DVET & 1 & 0.27 & 0.034 & 0.002 & 0.678 \\
\hline TORCH infection & 1 & 0.27 & 0.146 & 0.027 & 0.802 \\
\hline
\end{tabular}

Out of 110 neonates, 67 received ototoxic medications. At discharge 5 of them had abnormal BERA. But all these five were associated with other risk factors. Among all risk factors TORCH infection and hyperbilirubinemia in Exchange transfusion range are statistically significant with p-value $<0.05$ (Table 3 )

\section{Discussion}

Hearing impairment is a well - known problem in high risk NICU graduates. Left undetected, hearing impairment in infants can negatively affect speech and language acquisition, academic achievement, and social and emotional development. These negative effects can be diminished and even eliminated through early intervention at or before 6 month of age [8].

The incidence of hearing impairment in high risk infants according to different studies varies from 1\% to 40\% [6, 9-11]. There are several risk factors which are important as precipitator events, causing hearing impairment in newborn and young infants. The following are among these risk factors prematurity, low birth weight, asphyxia, use of aminoglycosides, hyperbilirubinemia, prolonged mechanical ventilation, meningitis, intrauterine infection and craniofacial anomalies [7].

We have used BERA for assessing hearing impairment which has important characteristics- it gives the electrophysiological response of hearing without any need for assessment of the newborn behavior, the result of this study are not affected by anesthetics or sedatives, which may be used during the test, BERA is rapid, easy and relatively cheap test.

The reported sensitivity of BERA for hearing assessment was 100\% and specificity around 97\% [12]. There were 110 high risk neonates during a study period from November 2012 to November 2013. The mean age of neonates who underwent BERA at discharge is $19.32 \pm 11.3$ days.

Preterm were screened after 37 gestational weeks. The mean birth weight of high risk neonates in the study is $2.60 \pm 0.67$ $\mathrm{kg}$. There was male preponderance of high risk neonates in our study. $68.2 \%$ are males and $31.8 \%$ are females. Of the neonates with hearing impairment $71.5 \%$ are males and $28.5 \%$ are females.

Ours is a tertiary hospital with no maternity center, so all cases are referred from different centers, and there is a bias in the number of male and females, term and preterm babies. As the number of preterm and low birth weight babies are less in our study, the mean birth weight in the study is in higher range.

In our study, Mode of delivery, Sex of the neonate and Birth weight has no significant correlation with hearing impairment. These results are in concordance with study of Christine Ohl et al in which birth weight and mode of delivery doesn't have significant correlation [13] Whereas study by Taghdiri et al showed significant relation with birth weight and caesarean section [2].

The incidence of hearing loss in our study at discharge was $9.1 \%(n=10)$ of high risk newborns, and on follow up after 3 months it was $6.4 \%(n=7) .30 \%$ of the neonates with hearing impairment had normal hearing when repeated after 3 months. In a study by Christiane Meyer et al on follow up of 31 infants with hearing impairment, 18 infants had persistent hearing loss (PHL) [14]. 
Table -4: Incidence of hearing impairment in comparison with other studies [2, 13-16].

\begin{tabular}{|c|c|}
\hline Study & Incidence \\
\hline Taghdiri et al & $4.07 \%$ \\
\hline Christine Ohl et al & $4.55 \%$ \\
\hline Christiane Meyer et al & $5 \%$ \\
\hline Our study & $6.4 \%$ \\
\hline Zamani A et al & $8 \%$ \\
\hline A.K.Gupta et al. & $19.2 \%$ \\
\hline
\end{tabular}

Among the neonates with hearing impairment, $71.4 \%(\mathrm{n}=5)$ had bilateral hearing loss and $28.5 \%(\mathrm{n}=2)$ had unilateral hearing loss.

The incidence of hearing impairment is high compared to some studies mentioned above. This may be due to hospital bias, as ours is a tertiary care hospital with predominantly sick cases. Family history of hearing loss, craniofacial anomalies are the two risk factors which were not studied, as there were no cases during the study period. 2 neonates were referred with TORCH infection, both had Rubella infection. Of them one (50\%) had severe hearing impairment, and the other had normal hearing. The neonate with abnormal BERA had bilateral cataract and PDA. Hearing impairment in TORCH infection is statistically significant in our study and is in concordance with study by Christine Ohl et al which also showed significant correlation between TORCH infections and BERA abnormality [13]. The incidence of hearing loss in congenital rubella syndrome is $67 \%$ [17].

The APGAR score is a method to assess the health of a newborn immediately after childbirth. Low APGAR scores are an indicator of perinatal hypoxia. It has been shown in animal models that the cochlear hair cells are sensitive to prolonged mild hypoxia [18]. The consequences of perinatal asphyxia range from death to various degree of neurodevelopmental sensory or motor deficits. In our study neonates were selected on Sarnat scoring, and not on APGAR scoring, as our hospital doesn't have internal maternity hospital and all neonates are referred from different centers and correct APGAR is not known.

$17.3 \%(\mathrm{n}=19)$ of high risk neonates had HIE. 5.2\% of them had abnormal BERA which is comparable to study by A.K.Gupta et al with $6.6 \%$ of them had abnormal BERA [16]. Whereas studies by Vohr et al. had higher incidence with significant association with abnormal BERA in neonates with low APGAR scores [19]. The one with abnormal BERA in our study had HIE-2, with history of oligohydramnios and fetal distress presented with lethargy and feeding difficulties.

Elevated levels of bilirubin are considered toxic for the auditory pathways and the central nervous system, and are included among risk factors for neonatal deafness and encephalopathies. Since BERA wave changes have been associated with hyperbilirubinemia in newborn, BERA monitoring of jaundiced infants may be an important clinical tool for detecting early reversible bilirubin injury. In all the neonates with hyperbilirubinemia, BERA testing was not done in the acute stage at admission. It is done at the time of discharge, as there is no availability of bedside BERA testing facility in our hospital.

$18.75 \%(\mathrm{n}=3)$ of the neonates with hyperbilirubinemia requiring exchange transfusion had hearing impairment, and is statistically significant as individual risk factor and also on logistic regression analysis. Results are comparable to study by Taghdiri et al [2]. The incidence in our study is low when compared to studies by Agarwal et al and A.K.Gupta et al which show $33 \%$ of them with abnormal BERA $[16,20]$.

Of the three neonates with hearing impairment in our study, one showed improvement in hearing from moderate to mild, and one neonate from severe to moderate hearing impairment. Neonates with hperbilirubinemia in phototherapy range 
dint show statistical significance. Only one of 34 neonates had hearing impairment, and in BERA repeated after 3 months there was no hearing impairment. Meningitis is a known cause of SNHL and is recorded in the list of risk factors for congenital hearing loss defined by the Joint Committee on Infant Hearing. One of the four with meningitis (25\% of them) had hearing impairment.

In our study there is no statistically significant correlation between meningitis and abnormal BERA. The overall incidence with meningitis inour study is $0.9 \%$, and these results are comparable to study by Taghdiri et al in which it is $1 \%$ and no statistical significance [2] where as in study by Christiane Meyer et al meningitis had significant correlation with abnormal BERA [14].

Preterm birth is one of the major cause of neonatal mortality and morbidity. Preterm infants are at an increased risk of complications including disabilities and impediments in physical growth and development. A mild hearing impairment early in life can significantly affect normal development of speech and language [21, 22].

Of the 27 preterm babies in the study, 7.4\% ( $\mathrm{n}=2)$ had hearing impairment. The incidence of hearing impairment with preterm babies is $1.8 \%$ at discharge. BERA is performed at age corresponding to 37 weeks of gestation. The incidence of abnormal BERA in preterm in our study correlates with study by A.K.Gupta et al which also showed $8.3 \%$ of them with abnormal BERA [16]. Also studies by Christiane Meyer et al and Christine Ohl et al studies also didn't show significant correlation with preterms and abnormal BERA $[13,14]$. However this finding of low incidence of hearing impairment may be explained by improved conditions of perinatal care and overall reduced incidence of complications of prematurity [14]. BERA when repeated after 3 months was normal in both the neonates.

Delay in electrical conduction through the process of myelination of the structures of the auditory pathway to the brainstem which is still under development which suggest that the degree of myelination and immaturity of nerve fibres of auditory pathways are some of the reasons for hearing impairment in preterms [23, 24].

In a study done by Robertson, prolonged oxygen supplementation was the most significant predictor for PHL overall and for severe/profound loss. Prolonged ventilation/oxygen use is a known risk factor for PHL [4].

Aminoglycoside (ototoxic medications) use is an important risk factor in our study which is in association with many other risk factors. $67(60.9 \%)$ of the high risk neonates were exposed to ototoxic medications and $5(7.4 \%)$ of them had abnormal BERA at discharge. The incidence of hearing impairment with ototoxic medications after 3 months is $1.8 \%$ $(n=2)$. Those two neonates were associated with other risk factors. In our study Aminoglycoside use was not statistically significant. Our study results are correlating with study by Christiane Meyer et al which also doesn't have significant correlation [14]. Where as in study by Zamani A et al, significant association with ototoxic drugs and BERA findings is observed [15]. Amikacin drug levels were not monitored in our patients because of cost issues.

Mechanical ventilation for $>5$ days was seen in 15 neonates $(13.6 \%)$, of which one had hearing impairment and is statistically insignificant. Repeat BERA after 3 months was also abnormal, showing moderate hearing impairment unilaterally (in right ear). Our study results are not correlating with study by Zamani A et al, which showed statistically significant association with BERA [15]. Where as in study by Christiane Meyer et al there was no significant association of mechanical ventilation and BERA [14].

The effects of hearing loss on speech and language development and functioning in daily life are determined by the degree of hearing loss of both ears. Unilateral hearing impairment does usually not cause as many problems in daily life as bilateral hearing impairment does. The majority of infants in our population with a symmetric or asymmetric sensorineural loss will be candidates for hearing aid revalidation based on the degree of hearing loss of their best hearing ear. 
From our study two risk factors, Hyperbilirubinemia in Exchange transfusion range and congenital rubella infection have significant association with abnormal BERA individually with p-values 0.028 and 0.011 respectively. On logistic regression analysis also both these risk factors are significant with p-values 0.027 and 0.027 respectively. However the number of TORCH infections in our study is very low to assess its relation with abnormal BERA.

In Taghdiri et al study, Hyperbilirubinemia, Birth weight $<15000 \mathrm{~g}$ and Caesarean section were found to have statistically significant correlation with abnormal BERA [2].

In the study by Aiyer, Parikh et al, they are Length of stay in the NICU, Gestational age, craniofacial anomalies and TORCH infections were found to be statistically significant [3].

Christiane Meyer et al done a multicentre trial and found bacterial infections, craniofacial abnormalities and familial hearing loss are significant risk factors associated with abnormal BERA [14].

From various studies, it seems that all high risk factors significantly affect hearing and will benefit from hearing assessment by using BERA at an early age. No child is too young for hearing evaluation.

Screening programme should be performed in the nursery and well-baby clinic during immunization in the first 6 months of age to avoid harmful effect on speech and language development.

But surprisingly, no dedicated national programme has been carried out so far in India, for early detection of hearing loss in infants. Neonatal screening can yield high returns.

The true value of screening may lie in identification of mild to moderate hearing losses that are amenable to treatment. High risk infants have substantially higher incidence of hearing loss. So at least all high risk infants must be screened for hearing impairment prior to discharge from hospital using BERA.

It is important to retest infants with abnormal initial ABR after 3 months and several times within the first year if abnormal responses persist.

Further studies are required for cost effectiveness in India before using as a screening tool for universal newborn hearing.

Limitations of the study: The number of cases during study period is small to derive confirmative conclusions. This study is carried out in a single center and may not be truly indicative of scenario in the community. Requires long term follow up to assess permanent hearing loss.

\section{Conclusion}

Hearing is not a visible disability. It commonly goes undetected until it affects the child's communication in the form of speech and language. This emphasizes the need for newborn screening.

Though congenital hearing loss contributes to a majority of hearing loss in children, it can also occur in the later periods also due to meningitis, encephalitis, complications of prematurity, etc., Screening programs should not only include newborn screening but screening in later periods also based on the risk factors.
BERA gives an accurate picture of hearing sensitivity. Hence, in all high-risk babies, BERA should be carried out as a routine procedure to detect hearing impairment. Regular follow-up should be done, and rehabilitative measures should be started as early as possible.

Funding: Nil, Conflict of interest: Nil

Permission from IRB: Yes

\section{References}

1. McClelland RJ, Watson DR, Lawless V, Houston HG, Adams D. Reliability and effectiveness of 
screening for hearing loss in high risk neonates. BMJ. 1992 Mar 28;304(6830):806-9.

2. Taghdiri MM, Eghbalian F, Emami F, Abbasi B, et al. Auditory Evaluation of High Risk Newborns by Automated Auditory Brainstem Response. Iran J Pediatr Dec 2008; 18(4): 330-334.

3. Aiyer RG, Parikh B. Evaluation of auditory brainstem responses for hearing screening of high-risk infants. Indian J Otolaryngol Head Neck Surg. 2009 Mar;61(1):47-53. doi: 10.1007/s12070-009-0034-4. Epub 2009 Mar 31.

4. Robertson CM, Howarth TM, Bork DL, Dinu IA. Permanent bilateral sensory and neural hearing loss of children after neonatal intensive care because of extreme prematurity: a thirty-year study. Pediatrics. 2009 May;123(5):e797-807. doi: 10.1542/peds.20082531.

5. Erenberg A, Lemons J, Sia C, Trunkel D, Ziring P. Newborn and infant hearing loss: detection and intervention. American Academy of Pediatrics. Task Force on Newborn and Infant Hearing, 1998- 1999. Pediatrics. 1999 Feb;103(2):527-30.

6. Sukumaran TU. Newborn Hearing Screening Program. Indian Pediatr. 2011 May;48(5):351-3.

7. World Health Organization. WHO: prevention of blindness and deafness.2013. http://www.who.int/pbd/ deafnee/hearing_impairment_grades/en/

8. Declau F, Boudewyns A, van den Ende J, Peeters A, Heyning P. Analysis of 170 referred neonates etiologic and audiologic evaluations after universal neonatal hearing screening. Pediatrics. 2008; 121(6): 1119-26.

9. Ansari MS. Screening programme for hearing impairment in newborns: A challenge during rehabilitation for all. Asia Pacific disability Rehabilitation Journal. 2004; 15: 83-89.

10. Bilgen H, Akman I, Ozek E, Kulekei S, Ors R, Carman $\mathrm{K}$ et al. Auditory brain stem response screening for hearing loss in high risk neonates. Turk J Med Sci. 2000; 30: $479-82$.
11. Morales SG, Poblano A, Galvan AR, Carrocera LAF. Auditory evoked potentials in children at neonatal risk for hypocusis. Pan Am J Public Health. 1997; 2(4): $232-37$

12. Oudesluys-Murphy AM, van Straaten HL, EnsDokkum MH, Kauffman-de Boer MA. [Neonatal hearing screening]. Ned Tijdschr Geneeskd. 2000 Mar 25;144(13):594-8.

13. Christine Ohl, Liliane Dornier, $\mathrm{Ce}^{\prime}$ cile Czajka, Jean-Claude Chobaut, Laurent Tavernier. Newborn hearing screening on infants at risk. International Journal of Pediatric Otorhinolaryngology. 2009;73: 1691-1695 DOI: http://dx.doi. org/10.1016/j. ijporl. 2009.08.027.

14. Christiane Meyer, Witte J, Hildmann A, Hennecke KH, Schunck KU, Maul K et al. Neonatal Screening for Hearing Disorders in Infants at Risk: Incidence, Risk Factors, and Follow-up. Pediatrics 1999; 104:900.

15. Zamani A, Daneshjou K, Ameni A, Takand J. Estimating The Incidence Of Neonatal Hearing Loss In High Risk Neonates. Acta Medica Iranica 2004; 42(3):176-180.

16. Gupta AK, Anand NK, Raj H. Evaluation of risk factors for hearing impairment in at risk neonates by brainstem evoked response audiometry (BERA). Indian J Pediatr. 1991 Nov-Dec;58(6):849-55.

17. Bess FH, Humes LE. Structure and function of the auditory system. In Audiology: the fundamentals. 4th ed. Philadelphia: Lippincott Williams and Wilkins; 2009, p.101 - 57.

18. Sawada S, Mori N, Mount RJ, Harrison RV. Differential vulnerability of inner and outer hair cell systems to chronic mild hypoxia and glutamate ototoxicity: insights into the cause of auditory neuropathy. J Otolaryngol. 2001 Apr;30(2):106-14.

19. Vohr BR, Widen JE, Cone-Wesson B, Sininger YS, Gorga MP, Folsom RC, Norton SJ. Identification of neonatal hearing impairment: characteristics of infants in the neonatal intensive care unit and well-baby nursery. Ear Hear. 2000 Oct;21(5):373-82. 
20. Agrawal VK, Shukla R, Misra PK, Kapoor RK, Malik GK. Brainstem auditory evoked response in newborns with hyperbilirubinemia. Indian Pediatr. 1998 Jun;35(6):513-8.

21. Sleifer P, da Costa SS, Cóser PL, Goldani MZ, Dornelles C, Weiss K. Auditory brainstem response in premature and full-term children. Int $\mathrm{J}$ Pediatr Otorhinolaryngol. 2007 Sep;71(9):1449-56. Epub 2007 Jul 13.
22. Guilhoto LM, Quintal VS, da Costa MT. Brainstem auditory evoked response in normal term neonates. Arq Neuropsiquiatr. 2003 Dec;61(4):906-8.Epub 2004Jan 6.

23. Roopakala MS, Dayananda G, Manjula P, Konde AS, Acharya PT, Srinivasa R, Nirmala KS. A comparative study of brainstem auditory evoked potentials in preterm and full-term infants. Indian $\mathrm{J}$ Physiol Pharmacol. 2011 Jan-Mar;55(1):44-52.

24. Casali RL, Santos MF. Casali RL ${ }^{1}$, Santos MF. Braz J Otorhinolaryngol. 2010 Nov-Dec;76(6):729-38.

\section{How to cite this article?}

Sudharahan Raj C, Reddy S.V. Hearing assessment in high-risk neonates by brain stem evoked auditory response (BERA) at a teaching hospital in rural Telangana. Int J Pediatr Res.2016;3(8):597-607.doi:10.17511/ijpr.2016.i08.09 